\title{
An Exploration of Study Spaces Among Chinese and Indian Graduate Students
}

\author{
Ibtihaj Alsadun ${ }^{1, ~ *, ~ K r i s t i ~ G a i n e s ~}{ }^{2}$, Michelle Pearson ${ }^{2}$, Lee Duemer ${ }^{2}$, Charles Klein ${ }^{2}$ \\ ${ }^{1}$ Interior and Environmental Design Department, University of Hail, Hail, Saudi Arabia \\ ${ }^{2}$ Interior and Environmental Design Department, Texas Tech University, Lubbock, Texas, USA
}

\section{Email address:}

ebtihaj12359@gmail.com (I. Alsadun),kristi.gaines@ttu.edu (K. Gaines), Michelle.Pearson@ttu.edu (M. Pearson), lee.duemer@ttu.edu(L. Duemer), charles.klein@ttu.edu(C. Klein)

${ }^{*}$ Corresponding author

\section{To cite this article:}

Ibtihaj Alsadun, Kristi Gaines, Michelle Pearson, Lee Duemer, Charles Klein. An Exploration of Study Spaces Among Chinese and Indian Graduate Students. American Journal of Art and Design. Vol. 6, No. 1, 2021, pp. 13-25. doi: 10.11648/j.ajad.20210601.13

Received: February 20, 2021; Accepted: March 4, 2021; Published: March 30, 2021

\begin{abstract}
Over the last 40 years, many environmental design researchers have examined the environment's impact on people and sought answers to questions on personal feelings with the environment and how people become attached to a place and develop feelings about it. Research in place attachment has primarily focused on the social aspect, leaving a gap in the literature related to concepts of the built environment. The present study seeks to fill this gap by addressing the issue of physical place attachment among specific groups of international graduate students at Texas Tech University, a large public university in West Texas. Previous studies focused on generic and largescale place concepts such as the physical neighborhood ambiance. This study, by contrast, examines how international students from China and India choose and develop an attachment to study spaces around the university. A grounded qualitative research design was selected as the exploratory method of studying how international graduate students select, interact with, and create an attachment to preferred study places on and off-campus. The researcher conducted semi-structured individual and focus group interviews with a purposive sample of 50 Indian and Chinese participants. The results revealed some similarities and differences between Indian and Chinese graduate students in their most and least-preferred physical design and ideal study places. Both groups preferred quietness and natural light. However, Chinese graduate students preferred to study alone, while Indian graduate students felt motivated and supported when studying with others.
\end{abstract}

Keywords: Study Spaces, Place Attachment, West Texas, Graduate Student, China and India

\section{Introduction}

Over the last several years, many environmental design researchers have examined the environment's impact on people and have sought answers to questions such as do personal feelings affect satisfaction with an environment, and how do people become attached to a place and develop feelings about it in the first place? People attach to a place for several reasons. For example, they develop memories based on living for an extended period in that place, childhood events that occurred there, people they met, and friendships they made there. Positive feelings about an environment assist people in feeling satisfaction, comfort, security, relaxation, and love about a place [32]. According to Giuliani attachment theory considers both personal emotion and the variance between behavior and attachment to an environment [10].

Kasarda \& Janowitz claim that most urban sociologists and community scientists investigate place attachment as the emotional relationship between individuals and places, such as home, city, and neighborhood. The idea of place attachment is a broad concept, involving social and psychological issues on a variety of scales from group to individual responses [17].

The following research study seeks to fill that gap in the literature by addressing the issue of physical place attachment among specific groups of international graduate students at Texas Tech University, a large public university in West Texas. Previous studies were focused on generic and largescale place concepts such as the physical neighborhood ambiance. This study will examine how international 
students from China and India choose and develop an attachment to study spaces within the university.

\subsection{Research Objective and Questions}

The study aimed to ask graduate students from China and India at Texas Tech University about how they adjusted to, made sense of, developed feelings for, and became attached to the physical places where they spend time studying. From this, several questions arise:

1) How do international graduate students select, interact, and create an attachment to preferred study places on and off-campus?

A. How do Indian students select, interact, and create an attachment to preferred study places on and off-campus?

B. How do Chinese students select, interact, and create an attachment to preferred study places on and off-campus?

C. What are the similarities and differences between how Indian and Chinese select, interact, and create an attachment to preferred study places on and off-campus?

2) What are the design features of the preferred study places, and how do those features affect their decision to study there?

A. What are the design features of the preferred study spaces for Indian students and how do those features affect their decision to study there?

B. What are the design features of the preferred study spaces for Chinese students and how do those features affect their decision to study there?

C. What are the similarities and differences between the design features of the preferred study places for students from India and China?

\subsection{Significance of the Study}

The findings of this study will add to the theory and research explaining the purposeful physical design of both interior and exterior places to enable more favorable place attachment by international graduate students and how these places could be integrated into efforts to further their education. This in turn could enable the development of techniques and interventions to aid students intending to become international students and focus efforts toward preparing for this experience ahead of their travels. Applying the findings of this research to orientation programs before becoming international students could intercept and possibly decrease potential future anxiety, stress, homesickness, and grieving.

\subsection{Definitions of Terms}

Place attachment. An affiliation and sense of connection between a person and a specific place causing feelings of comfort and security [18].

Place identity. Developing an emotional affective attachment or bonding to places. Environmental psychologists, Proshansky, Fabian, \& Kaminoff termed place identity, Tuan termed topophilia, and Relph termed rootedness $[29,37,30]$.
Place release. The state when a place becomes enjoyable by meeting old friends or becoming friends with other people in that place [24].

Place realization. The environmental ensemble of the place coupling its physical constitution, such as building or landscape, with certain social activities and meanings [24].

Place intensification. A well-crafted policy, design, and fabrication in increasing place quality. It is the degree of people's satisfaction with a place [24].

Place dependence. When a person perceives the strength of association between him/herself and specific places [34].

Transition. The process of moving between two generally stable timeframes in which an individual experiences an entry into a new life phase. [16].

\section{Review of Literature}

When international students relocate to a new environment, they face some difficulties, which could affect their well-being and academic performance [36]. International students, as a part of a university community that spends most of its time on campus, build attachments between themselves and the campus that can lead to positive emotions that can enhance their well-being, academic performance, and motivation. According to Hashemnezhad Heidari \& Mohammad place attachment affects people in terms of social interest, physical place, and cultural, personal, and memory experiences. Many studies identify the physical environment as an important factor in place attachment, having a direct role in student satisfaction, and an indirect role in place attachment [12].

\subsection{Physical Environment of College or University Campuses}

Physical environments can influence people and affect their behavior; where campus can be functional and symbolic. The symbolic aspect depends on the emblematic meaning from people's perspective; while the functional aspect of a campus environment relates to its design and build, which comprise nonverbal messages that users can understand and interpret [36]. For example, when people find a welcome sign in the entry of the building, but the building feels unwelcoming, that sense overrides the written message. In that situation, people feel an inconsistency, and the nonverbal message has more influence [35].

College and university campuses can simplify the physical environments by examining them from the viewpoint of a pedestrian. Pedestrian experiences and views the environment from different perspectives such as safety, functionality, pleasure, and learning. The safety category is the most important to a physical environment, which should be accounted for in campus planning [35].

Danger on campus comes in different ways such as health hazards, air pollution, noise, and the risks of robberies and personal assaults. Untermann Strange \& Banning argued that a pedestrian should have a good experience on campus including security, protection factors, coherence, and interest 
[35].

\subsection{Transition to a New Place}

People move to a new environment for different reasons. Sometimes, people seek a new job, education opportunities, healthcare services, or escape from an unsafe environment. This includes students who choose to move to a new environment. International students transmit to another country to complete their education. This transition may result in new meaning being assigned to a place. Sometimes, the meaning of place or home appears when people miss home, activities, and people from a place [4].

Transition theory, by Fisher (2000-2003) explains a person's physical change during the transition. This theory helps to understand people's emotions during the transition to a new environment. Fisher's personal transition curve has eight stages: anxiety, happiness, fear, threat, guilt, depression, gradual acceptance, and moving forward. These eight stages can lead to one or four pathway stages.

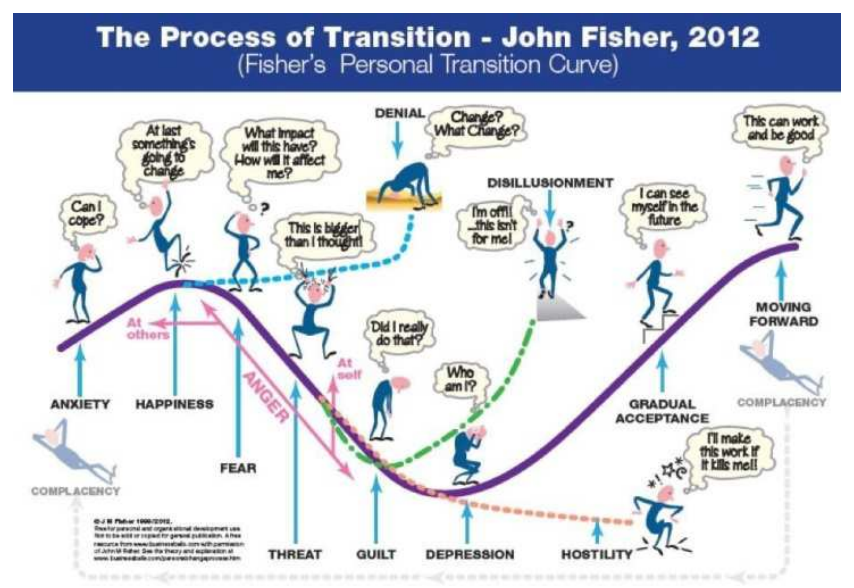

Figure 1. Fisher Transition Curve (Fisher, 2000-2003).

In a content analysis study of places favored by children of different ages, Korpela found that favorite places served a self-regulatory function that could enable place identity and place attachment [19]. In another study of New Zealand Maoris, Hay found that rootedness, or the bond between person and place, was necessary to integrate all kinds of life experiences into a meaningful life story, enabling a smooth transition from one life stage to another [13].

The longer people spend in a place the more they tend to be attached to the place. This proposition is a consistent predictor of place attachment in several studies Lewicka, Zajonc and Gifford et al posited that a longer duration of exposure that creates a positive familiarity leads to greater security [21, 40, 9]. Alternatively, Hay suggested that the passage of time enables aging and maturation that acquire meaning as in growing up, getting married, having a family, and growing old [13].

\subsection{Process of Attachment}

People could undergo a process attaching to places through seven patterns. First, place attachment in adult life depends upon place attachment in early life. The studies of Giuliani and Morgan made similar findings; showing that only people who develop place attachment in childhood would be able to develop effective bonding to places in adulthood [10, 26]. Similarly, several studies have associated successful exploration of the outdoors with the existence of place attachment development $[20,23,26]$, where outdoor exploration plays a key role in the development of mastery, self-efficacy, and affordances in children $[14,15]$.

The self-continuity related to place attachment was also found in a study by Lewicka who observed that people took an interest in family history related to the history of a family place as measured by Antoneovsky's Sense of Coherence Scale [21]. Similar findings were also reported in studies of individual and group-continuity that focused upon place identity as distinguished from place attachment Sani \& Twigger et al Moreover, the behavior is associated with building size $[31,38]$. The more extensive the process of people milling in and around larger buildings or structured places, the worse the upkeep of the surroundings, and the more negative and weaker are the neighborhood ties and place attachments [21]. In other words, each person has less control over the use of neighboring space as opposed to semi-private space [27]. This proposition fits with urban design theorists who have asserted similar propositions [2].

\subsection{Student Well-Being and Place Attachment}

Scannell \& Gifford stated that place attachment could be a part of an individual's well-being [33]. They found that by visualizing places of attachment ostracized participants experienced an improvement in three psychological aspects, meaning, and belonging. Scannell and Gifford's results could be implemented in a variety of places to provide well-being initiatives if more was known to designers about what aspects to implement. While researchers have found strong evidence for the role that place attachment plays in several settings, most of their research did not identify the specific physical elements of the environment that led to place attachment. Likewise, little research has compared participants from across various cultures.

\subsection{Student Academic Motivation and Place Attachment}

Academic motivation is the first step for students to achieve their goals in education. There are two types of academic motivation, intrinsic and extrinsic motivation. Intrinsic motivation refers to individuals' desires to do an activity for their satisfaction about what they are doing without any pressure from anyone $[6,7]$.

Intrinsic motivation relates to the psychological needs for efficacy and self-determination because completion of an activity for its own merits allows one to control the activity and exercise competence.

Intrinsic motivation toward stimulation that involves people interacting with the environment to feel competent. Intrinsic motivation toward accomplishments is about how a person participates in activities with satisfaction to experience 
achievement [39]. Intrinsic motivation is to experience stimulation when people experience feelings of cognitive pleasure via education. Moreover, extrinsic motivation is the motivation to engage in an activity as a means to an end $[5,39]$.

\section{Methodology}

A descriptive grounded qualitative research design was selected as the exploratory method of studying how international students identified, assigned meaning to, interacted with and experimented with, evaluated, described, selected, integrated, and become emotionally attached to preferred places to study on and off-campus. The qualitative approach allowed for semi-structured, open-ended questioning that enables researchers to delve into issues with greater probative power and relatively fewer restrictions than other approaches. This approach also was expected to provide detailed qualifying responses when the researcher seeks unknown perspectives and insights, deeper descriptions, and enhanced detail.

\subsection{Research Design}

Grounded theory research design was selected as the exploratory method of investigating the studying experiences that facilitate international students' transition from detachment from the physical design of places of their home countries to the attachment to the physical design of new places in which they have chosen to spend their graduate education.

\subsection{Sample}

A purposive sample of 50 participants was recruited. A sample of 10 had been shown to produce credible, meaningful interviews [3]. Around half the students were from China and the other half from India. Participants were at least 25 years of age with no chronic physical or mental health issues or criminal records.

\subsection{Materials and Instruments}

Semi-structured interviews were conducted using an interview guide protocol consisting of original, open-ended questions to allow maximum probative value for research purposes while offering the participants minimal restrictions in responding.

\subsection{Data Collection and Analysis}

The researcher contacted the director of the campus student clubs for Chinese and Indian students to request permission to recruit club members through their preferred communication channels. Moreover, the researcher contacted the graduate academic advisor in the Edward E. Whitacre Jr. College of Engineering to recruit more participants from India.

On the website, participants filled in their contact email and telephone/text number so that they can be contacted and notified in case of scheduling changes. Participants also were advised to write down the contact email and telephone information of the researcher, furnished on Qualtrics software, so they can notify the researcher of any unforeseen schedule changes on their end. Then they met the researcher individually at the scheduled interview time or at the scheduled focus group time. The interviews were audio-recorded.

Interview transcripts were compiled and analyzed using QDA Miner Lite. The researcher input the text into the software. The QDA Miner Lite computer software was programmed to code and analyze the interviews, produce frequency distributions of keywords and responses, and code text data into nodes and then subcategories of nodes.

\subsection{Data Credibility}

The study met most of the following criteria; following Guba standards to evaluate and confirm the study's credibility. The research design followed the procedures of an exploratory descriptive qualitative grounded theory research design that are generally established in the qualitative investigation [11].

\section{Results}

Fifty graduate students from China and India participated in this study. Twenty- six participants were interviewed individually, and twenty- four participants were interviewed in focus groups of six participants in each group. The sample students of this study come from a variety of majors to enrich the results with the perspectives of participants from different disciplines. Participants from China included 17 females and 8 males. One interview was conducted in a Teaching Assistant (TA) office at the Agricultural Sciences Building and the rest of the interviews were conducted at the graduate center.

1. How do international graduate students select, interact, and create attachment to preferred study places on and off-campus?

The purpose of the first question was to identify the study places preferred by international students and determine how they selected these places, why they chose them, and how they became attached to them. This question has three sub-questions specifying the populations of interest in this study.

A. How do Indian students select, interact, and create attachment to preferred study places on and off-campus?

The findings related to this question reveal the study places that students from India selected along with the reasons they chose these places and were attached to them. Most of the Indian students preferred the TA offices because they feel calm, convenient, and lead to focused work. The second most preferred study place among Indian students is off-campus, at home. Some Indian students have a small library in their home, access to other equipment, books, and notes. They also appreciate the availability of computers with two monitors and a whiteboard. In the library, Indian students find the environment to be calm, peaceful, and convenient. The frequency of preferred study places on and off campus between Indian students in order are TA offices (36\%) home $(28 \%)$, the graduate center, and library $(16 \%)$. One participant 
(4\%) preferred the Student Union Building (Figure 2).

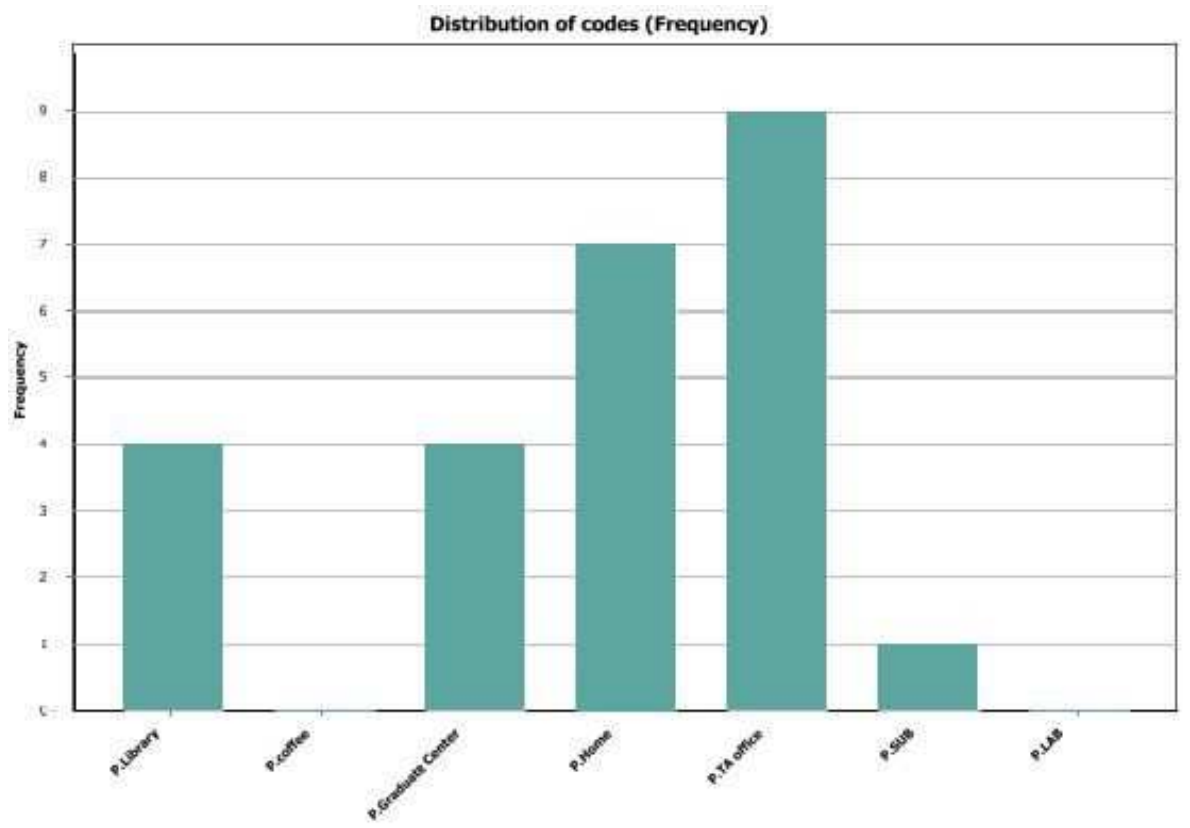

Figure 2. The preference study places among Indian graduate students.

In the analysis of participant responses, several themes of qualities of preferred study places emerged. The common features between the library and home were quietness, own space, available resources, concentration, ability to be alone. One participant stated:

Ms. Meera: "For me, I really want my space to be mine like very personal. I wanted to sit like kind of make that space and like next I have a library, small library in my house only. So, I don't prefer go to the library. Like I wanted to be with the books."

The second common features between preferences study place among the Indian students is studying with people around, which could find this feature at the library, TA office, Student Union Building, and graduate center.

Mr. Ishaan: “.... I have people in my office, if I have any difficulties, I can discuss with anyone out there. So that helps me in my study. That's what I like."

The least-preferred place to study among Indian graduate students. The frequency of least-preferred study places on and off campus among Indian students was the library (10 participants), home (5 participants), then TA offices (4 participants). Four Indian students chose different places that did not fall within a theme (Figure 3).

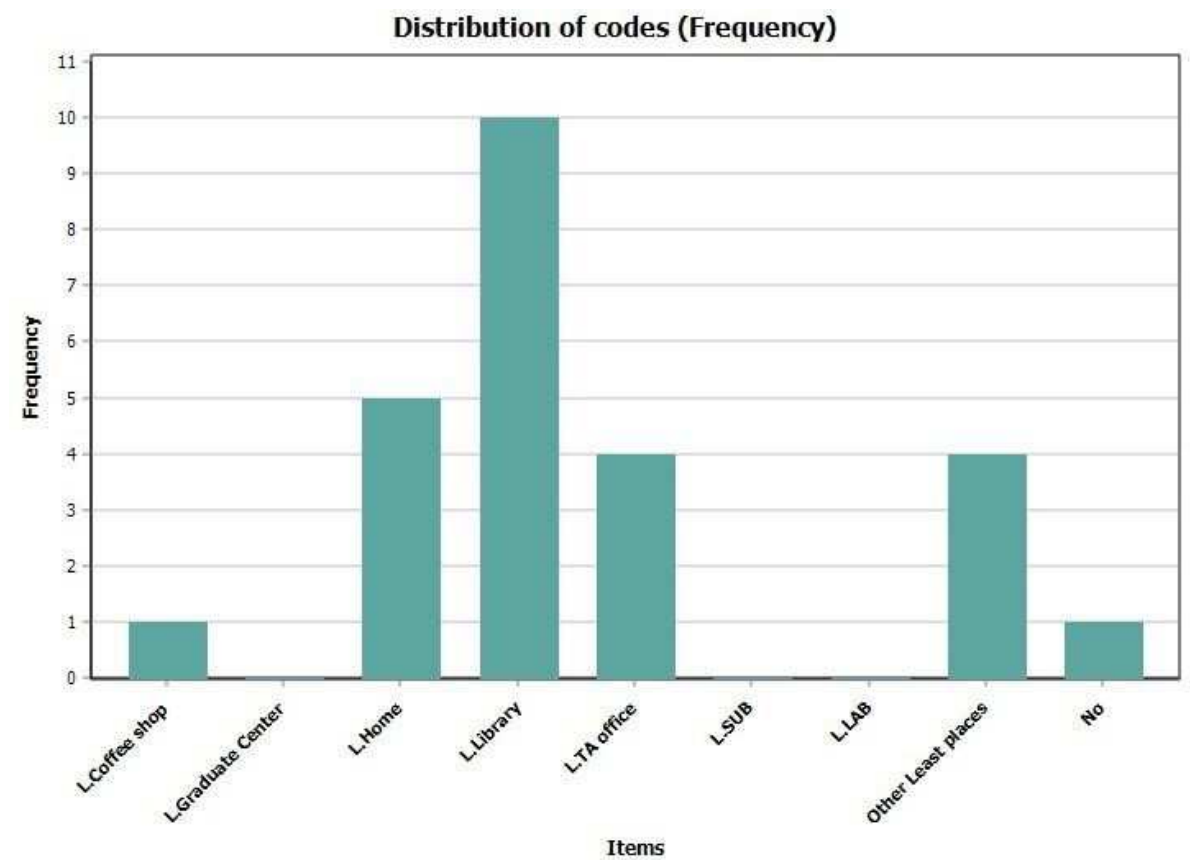

Figure 3. The least-preferred study places among Indian graduate students. 
The distractions from people around were common features of the least preferred study places among Indian students. As a participant stated:

Ms. Sahana: "I think only undergrads can study in library because most of the time they don't want to study and they just want us to have more social support from their friends and have a feel of being around people I cannot study in the library."

Some did not give any least-preferred places or named a place that did not fall within a theme. These participants described some features they did not prefer in study places.

Ms. Pari: "least favorite would be somewhere where people are all around and talking. So, I can't specifically tell a place, but just the environment where people are talking. So, where I cannot focus."

Off-campus current study places. Indian students described some benefits of studying at home that was in common with study places on campus. These features include quiet, having own space, and free of distraction from people. Participants said about home:

Mr. Arnav (about home): "It's quiet basically you can get comfortable because you have in back of your mind that you are at your own place. Everything is at your disposal. You can just hang, hanging around and places like in public place. So, you have to follow some etiquettes and be quiet and sometimes you just feel like going around and you don't focus or something."

On-campus current study places. The common benefit between the Student Union Building and the graduate center is the availability of a whiteboard. Other benefits were having people around and quiet, qualities used to describe the Student Union Building and some TA offices. The common benefits between the TA offices and the graduate center are that they are comfortable and have much equipment. Participant shared:

Mr. Reyansh (about TA office): "There's a TA room so I study in that room and over there we have got printers and all of the other facilities... I have two computers and then I have a very big, big desk. Also, I have got footrest. So, when a footrest, I like it personally, it's comfortable. The chairs are comfortable."

On-campus current study places. The common drawback feature of on-campus locations is that there is not enough space for students. However, they described specific drawbacks of each specific study place on campus. Some Indian students said the drawbacks of the library are that it is noisy, the computers are sometimes occupied, makes people sleepy and bored, distracting, has insufficient help staff. Participants said:

"The drawback for me in my office would be that it does not have windows, so he doesn't have a good ventilation or natural sunlight coming through. So that, that's the biggest drawback I would love to have like window sunlight."

Preferred study places and ideal features. This section presents the environment that Indian students imagine being an ideal study place. In describing their ideal study spaces, participants drew from their experiences in their preferred study spaces and their imagination of what would create a desirable space. Participant responded:

Mr. Reyansh: "I prefer studying alone, so when it's peaceful, it's not necessarily if the study spaces is large or small, but it should be peaceful and then I also prefer enough sunlight. There's enough light and ventilation as well... when there's a silence and when there's not a lot, not a lot of noise but then at the same time I can see people around that would be the best thing."

B. How do Chinese students select, interact, and create attachment to preferred study places on and off-campus?

The findings related to this question examine the study places that students from China selected and the reasons for their choices and their attachment to them. Most of the Chinese students preferred the library because they said it had a comfortable, quiet, focused environment and allowed ready access to books, software, and private study areas. Chinese participants found them motivating; quiet, if you share it with a smaller number of people; flexible; and convenient.

The frequency of preferred study places on and off campus among Chinese students is the library by (40\%), TA offices by $(32 \%)$, and then home by $(16 \%)$. One participant $(4 \%)$ preferred each the graduate center, student union building, and coffee shop (Figure 4).

The commonality features between preferred study places themes were quietness, comfort, convenience, motivation, and availability of resources and equipment. Ms. Ya and Ms. Ai both described their preference for the library.

Ms. Ya: "Library, because I feel like quiet there. Um, and also the environment is really good and also you can get some resources like some books and also some medias in there directly."

Ms. Ai: "Actually in the library, there is about the third floor, the second floor. There are some quiet space and in the booking area."

The second common features between preferred study places among the Chinese students are comfort and convenience, which characterized the library, TA offices, and home. Ms. Jia said that the library had a comfortable environment, and Ms. Luli said she was comfortable in the library because it offered multiple choices of seating areas.

Ms. Jia: "I think library much quieter, and the environment is much more comfortable."

Ms. Luli: "Library. It makes me feel like a comfortable space and have multiple choice."

The third common features of the preferred study place among Chinese students were motivation and availability of resources and equipment, included in descriptions of the library and TA offices.

Ms. Jie: "I feel in the library... and most people are focused on their study. So, ... you cannot be distracted at other things. And another thing is the library the Internet, the computer is very good." 


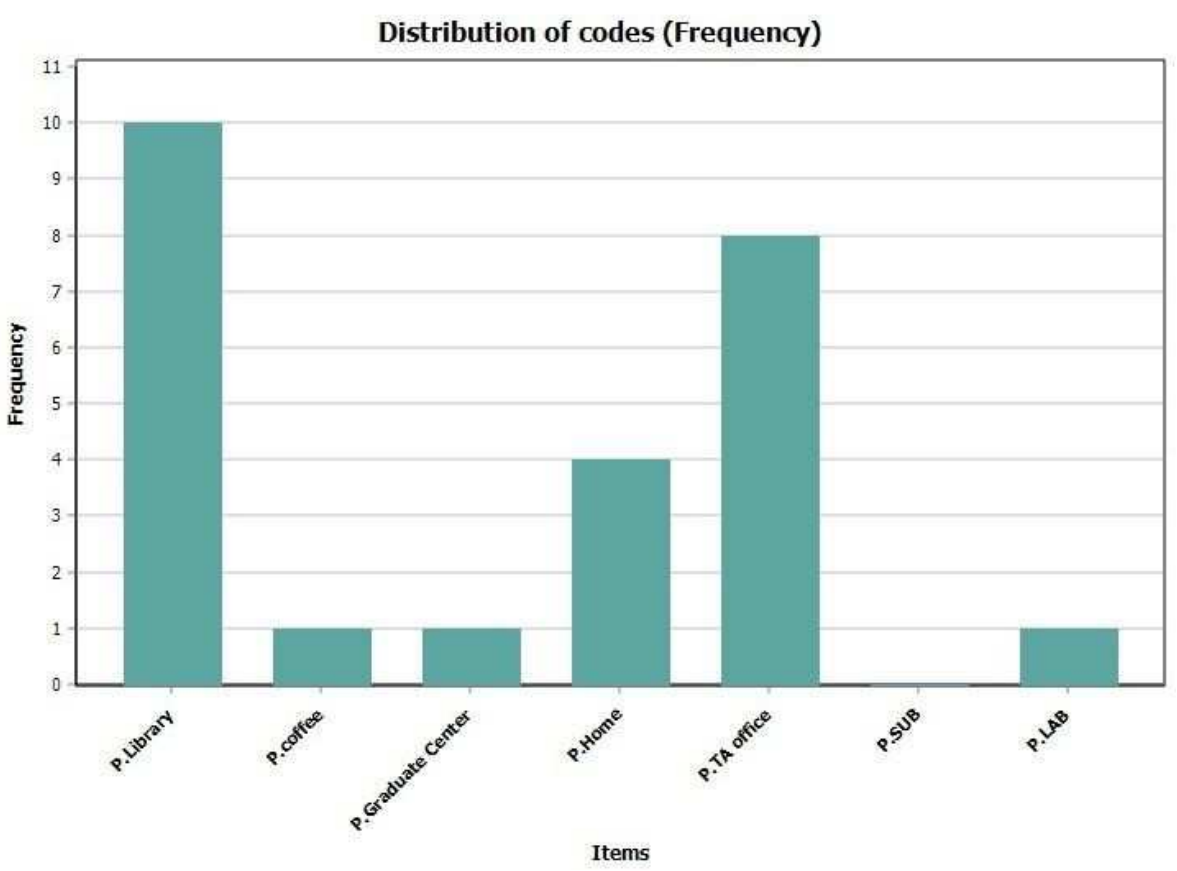

Figure 4. The preferred study places among Chinese graduate students.

C. What are the similarities and differences between how Indian and Chinese select, interact, and create attachment to preferred study places on and off-campus?

The findings of this question examine the places where students from India and China were selected and the way they were attached to these places. These findings illuminated the similarities between the Indian and Chinese students the study places on and off-campus. The findings are summarized in Table 1.

Table 1. Similarities between Indian and Chinese Graduate Students.

\begin{tabular}{|c|c|c|c|}
\hline Themes & Indian & Chinese & Similarities \\
\hline Most preferred & TA offices & Library & \\
\hline $\begin{array}{l}\text { Reason for } \\
\text { preference }\end{array}$ & $\begin{array}{l}\text { Solitary, some people around, window, } \\
\text { less distraction }\end{array}$ & Convenient, motivating, available equipment & $\begin{array}{l}\text { Quiet, comfortable, available study } \\
\text { resources }\end{array}$ \\
\hline Least preferred & Library & Home & \\
\hline $\begin{array}{l}\text { Reason for least } \\
\text { preferred }\end{array}$ & Small place for individual study room & $\begin{array}{l}\text { Noise, inappropriate temperature, no window, } \\
\text { uncomfortable seating }\end{array}$ & People around, distraction, \\
\hline $\begin{array}{l}\text { Common } \\
\text { benefits }\end{array}$ & $\begin{array}{l}\text { Whiteboard, people around, comfortable } \\
\text { own space }\end{array}$ & $\begin{array}{l}\text { Books, furniture chair and table, outlets, water } \\
\text { fountain, variety of seating }\end{array}$ & $\begin{array}{l}\text { Quiet, access to data, equipment, } \\
\text { computer }\end{array}$ \\
\hline $\begin{array}{l}\text { Common } \\
\text { Drawbacks }\end{array}$ & Noise & Open space, lack of safety & $\begin{array}{l}\text { A lot of people, People talking, lacking } \\
\text { window airflow, distraction, insufficient } \\
\text { space, uncomfortable temperature }\end{array}$ \\
\hline $\begin{array}{l}\text { Features of } \\
\text { ideal study } \\
\text { space }\end{array}$ & $\begin{array}{l}\text { Personal space, and comfortable seating } \\
\text { arrangement, enough and appropriate } \\
\text { light, good ventilation, printer, good } \\
\text { internet connection, charging }\end{array}$ & $\begin{array}{l}\text { New clean large table with personal space, } \\
\text { privacy, not very open to reduce people } \\
\text { interruptions, big windows, natural light, } \\
\text { colorful design, some plants, flowers, some art }\end{array}$ & $\begin{array}{l}\text { Quiet, comfortable furniture, computer } \\
\text { with two monitors, vending machine, } \\
\text { food and water }\end{array}$ \\
\hline
\end{tabular}

2. What are the design features of the preferred study places and how do those features affect their decision to study there?

The findings related to the second question were the preferred design features of ideal study places as identified by international students. This question has three sub-questions.

A. What are the design features of the preferred study spaces for Indian students and how do those features affect their decision to study there?

The findings related to this question reveal the design features of ideal study places that students from India preferred. The important elements and characteristics of ideal study places. The common important features among Indian participants are silence, proper lighting, natural light, a computer with two monitors, an internet connection, a printer, and a table and chair. In participant' words:

Mr. Aarav: "So, having a computer with strong Internet connection and a silence around the area. If it's like too crowded, too disturbing, then obviously even if you have a good desk, good computer, it's still really not really helpful. So, maybe a quiet place."

The design elements that must be included in interior study places from Indian students' perspective are quiet, open environment, comfortable table, quality air condition, relaxing pictures, and seating on the floor with a backrest. One participant shared their thoughts:

Mr. Aarav: "I need to have a like a desk in front of me so that I can like jot down points right when required and really needs to have a computer in front of me I prefer that. Prefer a chair with a 
backrest so that we can relax for whenever we are typing."

Memory Stimulation of Indian Students

The current study concentrated on design features. However, in the data analysis, unexpected themes emerged around participants' reflections on study places back home, especially for participants from India. Those reflections were primarily prompted by questions about why students leave a study place in the United States. This theme of memory stimulation had three subthemes: memories of study spaces, memories of leaving a study space, and memories of social experiences in places.

The memory of study spaces for Indian students back home. Memories from back home relate to memories of places in which the participants studied in their home country. Remembering features of a study place indicates that they were attached to those places. Seven participants had memories of their study place in India. The design features they had described in their study places were quiet, private, near to nature, outdoor space near a garden, natural ventilation (without air conditioning), and specific furniture.

Ms. Izna: "My places back in my home country. I used to sitting on garden at my grandparents. They used to have a garden. I used to just go on top of the forest and uh, just sit down and carry a few books. Mostly I liked sitting beside the plants and studying."

Reasons for leaving study places. Indian students experience some incidents that affect their concentration and make them leave study places. According to Indian students, they leave study places because the spaces are crowded, noisy, lack light or natural light, have an improper temperature, people talking loudly, small cubicles or small claustrophobic space, broken furniture, or weak internet connection. One participant shared their experiences:

Mr. Krish: "Would be small claustrophobic spaces on the second floor and third floor of library. Um, that's the first problem. Yes ... One of the problems that I left the library, small cubicles in the library because, um, it was winter time."

Social life. Indian students have different experiences of social life in the United States and back home, which can affect their attachment and what they miss. Sixteen participants reported that they missed their home versus nine who do not miss their home country. One participant said:

Mr. Vivaan: "I think it's more of the, so our genetic make-up might be different than the people in the U.S. the preference to be too cold, I have seen people walking out with coke in their hand when it is snowing outside... we do not prefer that we prefer hot tea."

B. What are the design features of the preferred study spaces for Chinese students and how do those features affect their decision to study there?

The findings related to this question reveal the design features of ideal study places that students from China would prefer to increase the attachment to the study space. The important elements and characteristics of ideal study places. Chinese students have some elements and characteristics of study spaces they find valuable. These include a quiet and safe environment, a computer, internet, and an appropriate temperature. One participant shared their thoughts:
Ms. Niu: "I hope they can offer some big screen computers and uh, if the place have drinking water that were be so good for us. Yeah and uh, oh, I hope, I also hope they can offer us some hot water because for Chinese people sometimes they like drink warm water instead of cold water. Yeah. So I hope they can have such service."

Memory Stimulation of Chinese Students

In participants' discussion of their ideal study places, many Chinese students reflected on their previous experiences with study places in their home country, which was unexpected. The participants' responses made it clear that their previous experiences with study experiences in their home cultures greatly informed their preferences. Therefore, the theme of memory stimulation emerged from the data.

The memory of study spaces for Chinese students back home. Memories of home relate to the place that participants studied in their home country. If they remember any features, they attach to them. Only one participant from China had a memory from back home, which was meeting with her colleagues in a restaurant, and having fun discussing their ideas and work in an informal setting, building collegiality.

Ms. Jie: "In China, Chinese people like to get together to have it, have dinner in a restaurant. Sometimes we talk about the academic things. Yes. But in, in U.S., there is no this tradition, everybody study individually there. If we talk about this theme in a table in the restaurant, oh, we'll think, oh, maybe my advice, my suggestion is not so."

Reasons for leaving a study place. Chinese students experience some incidents that happened to the participants that affected their studying and made them leave the study place. Chinese students leave their study places if there is noise, which could interrupt their studying. One participant shared their experiences as follows:

Mr. Gang: "It's basement so I cannot see the sunlight. You know, if you stay in the basement you don't feel very comfortable. So, I just want it to go outside to go into the sunlight to get us some sunlight to walk to make myself feel, feel comfortable. So that's the thing I did frequently."

Social life. Chinese students experience a social life in the United States or their back home that could affect their attachment and what they miss. Participants talked about their experience as international students in the United States, one feels unwelcome and the other one feels that most American students prefer individual study.

Ms. Rong: "I feel like people here are not very welcoming international students. I could feel that in my department. And, uh, also when I talk to people, people are not very welcoming because they are so conservatives."

C. What are the similarities and differences between the design features of the preferred study places for students from India and China? What are the similarities and differences in why these design features affect their decision to study there?

The findings related to this question present the design features of study places preferred by students from India and China. In this section, the similarities and the differences between Indian and Chinese graduate participants about the study places on and off campus are discussed. These findings 
are summarized in Table 2; showing the design features of the preferred study places for students from India and China and

the reasons behind such aspects.

Table 2. Similarities and differences in design features for Indian and Chinese students.

\begin{tabular}{llll}
\hline Themes & India & China & Similarities \\
\hline $\begin{array}{l}\text { The important } \\
\text { and essential } \\
\text { elements }\end{array}$ & $\begin{array}{l}\text { Internet, hot and cold food, drink service, acoustics, window with } \\
\text { a view, ventilation, floor seating, power outlets, colorful wall. }\end{array}$ & $\begin{array}{l}\text { Whiteboard, water, proper white light and } \\
\text { natural light, computer with two monitors, } \\
\text { printer, comfortable chair, comfortable table. } \\
\text { Quiet, private, near to nature, outdoor space near a garden, no air } \\
\text { Beeting with colleagues in a restaurant and } \\
\text { conditioning, windows to provide natural ventilation, variety of } \\
\text { discussing work matters in an informal } \\
\text { setting in an informal tone. }\end{array}$ & $\begin{array}{l}\text { China } \\
\text { furniture, special furniture, adjustable window, colorful wall. }\end{array}$ \\
$\begin{array}{l}\text { India } \\
\text { Must be }\end{array}$ & $\begin{array}{l}\text { Background music, a lot of furniture, yellow light, mess, small, people talking with each other } \\
\text { table, sculpture in study place without purpose, and office mate. }\end{array}$ & $\begin{array}{l}\text { or with a phone, furniture with picky texture } \\
\text { or weird sound, and garbage. }\end{array}$ & $\begin{array}{l}\text { Distraction and } \\
\text { discomfort. }\end{array}$ \\
\hline
\end{tabular}

\section{Debriefing Questions}

At the end of the interview, the researcher sent four debriefing questions to the participants. Forty- three participants out of fifty answered the debriefing questions. The debriefing questions were to ensure the level of comfort of the participants during the interview. The following questions were asked: 1) Were the questions that the researcher asked to address what you expected would be asked in this study? 2) Were there any questions that should have been asked, but were not? 3) Were there any inappropriate questions? 4) Do you think too much time was spent on the interview?

For the first question, table 3 shows the answers

Table 3. Were the questions that the researcher asked to address what you expected would be asked in this study?

\begin{tabular}{lll}
\hline Answer & Percentages & Number of participants \\
\hline No & $2.33 \%$ & 1 \\
A little & $6.98 \%$ & 3 \\
Somewhat & $16.28 \%$ & 7 \\
Mostly & $13.95 \%$ & 6 \\
Yes & $60.47 \%$ & 26 \\
Total & $100 \%$ & 43 \\
\hline
\end{tabular}

For the second question, table 4 shows the participants' answers.

Table 4. Were there any questions that should have been asked, but were not?

\begin{tabular}{lll}
\hline Answer & Percentages & Number of participants \\
\hline No & $34.88 \%$ & 15 \\
I do not think so & $46.51 \%$ & 20 \\
Maybe & $13.95 \%$ & 6 \\
A few & $2.33 \%$ & 1 \\
Yes & $2.33 \%$ & 1 \\
Total & $100 \%$ & 43 \\
\hline
\end{tabular}

For the third question, table 5 shows the participants' answers.

Table 5. Were there any inappropriate questions?

\begin{tabular}{lll}
\hline Answer & Percentages & Number of participants \\
\hline No & $83.33 \%$ & 35 \\
Cannot think of any & $11.90 \%$ & 5 \\
There could be & $0.00 \%$ & 0 \\
Maybe some & $0.00 \%$ & 0 \\
Yes & $4.76 \%$ & 2 \\
Total & $100 \%$ & 42 \\
\hline
\end{tabular}

For the fourth question, table 6 shows the participants' answers.

Table 6. Do you think too much time was spent on the interview?

\begin{tabular}{lll}
\hline Answer & Percentages & Number of participants \\
\hline No, not enough & $11.63 \%$ & 5 \\
More would be & $4.65 \%$ & 2 \\
better About right & $76.74 \%$ & 33 \\
Less would be & $6.98 \%$ & 3 \\
better & $0.00 \%$ & 0 \\
Yes, too much & $100 \%$ & 43 \\
\hline
\end{tabular}

\section{Discussion}

Research in place attachment has primarily focused on the social aspect, leaving a gap in the literature related to the built environment. The current research study sought to fill that gap in the literature by addressing physical place attachment among specific groups of international students at Texas Tech University, a large public university in West Texas. Previous studies focused on generic and largescale place concepts such as the physical neighborhood ambiance. This study, by contrast, will examine how international students from China and India become comfortable with, and form attachment to their chosen study spaces within the university. Students from China and India were asked about how they adjusted to, made sense of, developed feelings for, and became attached to the physical places where they spend time studying. The research questions were formulated to draw distinctions between alternative approaches to identifying, evaluating, developing feelings for, and becoming attached to the design features of places that international students preferred in their selected places.

The primary two research questions of this study are as follows: (1) How do international students select, interact with, and create an attachment to preferred study places on and off-campus? (2) What are the design features of the preferred study places and how do those features affect their decision to study there? To answer these questions, the researcher conducted semi-structured interviews among international students from India and China. Participant responses confirmed some of the existing literature and revealed new insights in place attachment. The results have important implications for designers and researchers. In the following sections, the results for each research question will be 
discussed.

\section{Findings}

1. How do international graduate students select, interact, and create attachment to preferred study places on and off-campus?

The findings of the first questions supported some of the findings of previous literature related to place attachment. The first outcome was revealing the features of current study places that the participants considered as important to their satisfaction in those study places. According to Moore \& Graefe physical design features can assist to improve the meeting of people's needs, which could increase people's attachment to the places [25]. Findings of the preferred places to study showed that 17 participants preferred to study in the TA offices. The second most preferred location, selected by 14 participants, was the library. These findings align with the findings of Moore \& Graefe in that people preferred these study places because their needs were served in these places [25].

The participants also described their least-preferred study locations. Six Chinese students least preferred studying at home and ten participants from India least preferred the library. Chinese participants' responses revealed that they did not prefer to study at home because of distractions from the bed and TV. Participants from India did not prefer the library because of the distractions of other people. Therefore, these places could not meet students' study needs, meaning that they may not attach to those locations [25].

The results also revealed the benefits and drawbacks of preferred study places. From Moore \& Graefe perspective, if the place meets the person's needs and satisfaction, then the person will become attached to the place. These places could not satisfy the participants' needs [25]. These findings aligned with the findings of Abdelmonem who investigated the physical design characteristics that may reduce depression among the elderly in long-term care facilities. One of the findings of this study suggested access to dynamic views and access to nature. Windows and airflow are important features to increase place attachment [1].

Chinese students prefer a familiar space with a sense of belonging and love because it gives feelings of comfort. In fact, many of the students from both groups preferred to study in the TA offices. According to Oishi et al a familiar location has a more positive effect than an unfamiliar location. The findings revealed the study space design features are most preferred by participants [28]. Overall, the participants' expectations for study places were quietness, convenience, comfort, open space, appropriate lighting and temperature, a big window, comfortable chair and table, computer with two monitors, vending machine, and easy access to food and water.

2. What are the design features of the preferred study places and how do those features affect their decision to study there?

According to the findings from the second question, there were certain features of the places in which participants from India and China most prefer to study that most affect their desire to study there. Participants from both groups prefer acoustics, proper white light, and natural light, a computer with two monitors, a printer, a comfortable chair with armrest and backrest, and a comfortable adjustable table.

Most of the Indian and Chinese participants did not prefer to study in small places such as a cubical. Besides, the participants did not prefer wooden chairs because they were not comfortable for an extended period. They prefer open space with clearly defined individual study places, which helps to reduce the distraction of people who walk around while also allowing them to not feel isolated. Most of the Chinese participants wish to have solitary study spaces, but a few Chinese participants and most of the Indian participants want to study around people. Access to others allows the students to find someone to assist them when they need collaborative help and to feel motivation from others who are studying. This preference to study with others is supported by the findings of $\mathrm{Li}$ who found that a good social life predicted higher attachment and motivation [22] . Likewise, [36] Terrazas et al found that campus features could be experienced at a personal level while also allowing for social interaction between other students [36].

Features not related to physical design. In addition to the physical design features of the places in which they study, the participants also described relevant features that were not a part of the physical design. The participants from China and India found the temperature on the campus to be uncomfortable most of the time, usually feeling too cold. Participants referred to cultural differences that affected U.S. and international students' needs. Additionally, some participants from China and India wished to have a water kettle. The Chinese participants stated that they prefer to drink hot water and the Indian participants preferred to drink hot tea. In addition to environmental features, international students' social life could affect their attachment to the place.

Three participants cited cultural differences that could affect their attachment. The first participant expressed a preference for informally meeting with colleagues, as opposed to the more formal U.S. style. The second participant expressed the feeling of unwelcoming, which could come from the difference between campuses in their home country and U.S. campuses. The third participant stated body differences between U.S. and international students as it relates to the ability to tolerate colder temperatures.

\section{Implications for the Study}

This study aimed to examine how international students from China and India become comfortable with, and form attachment to their chosen study spaces within the university. This study has rich results of design features details that could enhance place attachment, which could lead to improve academic motivation and motivation between international students. The present research provides details of design features and needs between international students that could enhance their attachment to study places and make them spend more time in these spaces. These findings could be helpful for 
any designer who is interested to design education facilities especially college or university facilities.

These findings could be helpful to use in orientation programs for international students before their traveling to a new environment and country to decrease potential future anxiety, stress, homesickness, and grieving. Students should know what lies ahead of their decision to become students outside of their home countries and be prepared to resist the temptation to drop out of their programs through knowledge of alternative approaches to addressing expected frustrations, anxieties, and having spaces that could enhance their attachment.

\subsection{Implications for Place Attachment Theory}

The findings of this study have important theoretical implications by giving an insight view about specific features of a design that could increase place attachment in study places among international students. Most of the research in the place dimension of place attachment theory ascribes the same role to physical and social aspects in place attachment. This has left a gap in the literature related to the built environment in place attachment theory. The findings extend and develop place attachment theory by showing how students develop an attachment to specific study spaces around the university and how international graduate students select, interact with and create an attachment to preferred study places on and off-campus.

This study used grounded theory research to develop place attachment theory. This study presented details of design features that increase place attachment in study places such as quietness, comfort, and availability of resources, equipment, amenities, open space, appropriate lighting and temperature, a big window, comfortable chair and table, computer with two monitors, vending machine, and easy access to food and water. The findings of this study could develop the place attachment in place dimension in the physical aspect. The physical environment itself could impact and increase place attachment if it meets people's needs by providing previous features. The social and place aspects in place attachment theory may affect each other but they do not play the same role in place attachment. People could be attached to a place because of the design features themselves.

\subsection{Cross-Cultural Implications}

The findings in cross-cultural could be generalized in any community from small to large society. The comparison between the two cultures gives uniqueness and similarities to these cultures. From this perspective, the findings could be applied in college and university facilities by applied the similarities of the preferred features in study places. Additionally, the findings provide unique features, which could give an insight view about ideal study places for international students. Furthermore, this study found some features that could be applied in study places and appropriate for some or even all humans' cultures such as quietness, appropriate furniture for a long time sitting, private areas, availability of equipment and sources, and more.

\section{Recommendations}

Study place design should meet international students' needs to increase their attachment, satisfaction, and motivation. Most of the participants preferred big windows intending to provide natural light and relaxation when they need it. They also want to have access to equipment such as a computer with two monitors, a printer, and supplies. Furthermore, they need access to amenities such as a vending machine, water fountains, and ready access to restaurants. The participants tried to avoid noisy and crowded study places. There are several ways to avoid that distraction from people on campus. In offices, the number of users should be minimized. In open spaces, there should be areas with equipment such as printers, computers with two monitors, sufficient power outlets, and comfortable tables and chairs.

\section{Limitations of This Study}

The findings of this study cannot be generalized to international students in the United States due to a number of limitations. The first limitation is the use of purposive sampling of international students at Texas Tech University. Since this study focuses only on the Texas Tech University campus, that could limit the physical design features. Having many different campuses could increase the physical design features that prefer by international students. The second limitation is the inclusion of only two international student populations, which are not representative of any other international student populations. Furthermore, including a greater variety of populations would provide deeper insights about a greater number of cultures, which would likely yield new preferred features in study places.

\section{Conclusion}

Findings of the preferred places to study showed that 17 participants preferred to study in the TA offices. The second most preferred location, selected by 14 participants, was the library. The participants also described their least-preferred study locations; as six Chinese students least preferred studying at home and ten Indian participants least preferred the library. Chinese participants' responses revealed that they did not prefer to study at home because of distractions from the bed and TV. Participants from India did not prefer the library because of the distractions of other people. The findings also suggested access to dynamic views and access to nature; where windows and airflow are important features to increase place attachment. Furthermore, the findings revealed the most preferred design features of the study space for the participants; as their expectations for study places were quietness, convenience, comfort, open space, appropriate lighting and temperature, a big window, comfortable chair and table, computer with two monitors, vending machine, and easy access to food and water. Study place design should meet 
international students' needs to increase their attachment, satisfaction, and motivation. Most of the participants preferred big windows intending to provide natural light and relaxation when they need it. They also want to have access to equipment such as a computer with two monitors, a printer, and supplies.

\section{Acknowledgements}

I thank God who allowed me to live this moment of happiness and achievement. I would like to thank my committee chairs, Dr. Kristi Gaines and Dr. Michelle Pearson, who were generous in providing me with their knowledge, experience, and time. Next, I would like to thank my committee members, Dr. Charles Klein and Dr. Lee Duemer, who were patient and wise and made me a better qualitative researcher. I owe a special thanks to my family, who have been there for me since day one. If it were not for them, I would not be who I am today.

\section{References}

[1] Abdelmonem, M. 2016. Identifying physical design of connectedness-to-home among depressed elderly in long-term care facilities: An exploratory study (Doctoral dissertation). Retrieved from https://ttu-ir.tdl.org/ttu-ir/handle/2346/68106.

[2] Alexander, C., Silverstein, M., Angel, S., Ishikawa, S., \& Abrams, D. 1977. A Pattern Language. Oxford, UK: Oxford University Press.

[3] Boddy, C. R. 2016. Sample size for qualitative research. Qualitative Market Research: An International Journal, 19, 426-432. Doi: 10.1108/QMR-06-2016-0053.

[4] Case, D. 1996. Contributions of journeys away to the definition of home: An empirical study of a dialectical process Journal of Environmental Psychology 16, no. 1: 1-15.

[5] Cunningham, K. R. 2013. The Effect of Motivation on Student Success in a First-Year Experience Course (Unpublished doctoral dissertation). Western Kentucky University, Bowling Green, KY.

[6] Deci, E. L. 1975. Intrinsic Motivation. New York: Plenum Press.

[7] Deci, E. L., \& Ryan, R. M. 1985. Intrinsic Motivation and Self-Determination in Human Behavior. New York, NY: Plenum Press.

[8] Fisher, J. 2000-2003. Personal Transition Curve concept and content. Fisher \& Savage Personal Construct Psychology.

[9] Gifford, R., Scannell, L., Kormos, C., Smolova, L., Biel, A., Boncu, S. 2009. Temporal pessimism and spatial optimism in environmental assessment: An 18- nation study. Journal of Environmental Psychology, 29, 1-12.

[10] Giuliani, M. V. 2003. Theory of attachment and place attachment. In M. Bonnes, T. Lee, and M. Bonaiuto (Eds.). Psychological theories for environmental issues. Pp., 137-170. Aldershot, UK: Ashgate. Retrieved from: https://www.researchgate.net/publication/228091197_Theory_ of_Attachment_and_Place_Attachment.
[11] Guba, E. G. 1985. The context of emergent paradigm research. Organizational theory and inquiry: The paradigm revolution, 79-104.

[12] Hashemnezhad, H., Heidari, A., \& Mohammad Hoseini, M. 2013. Sense of Place and Place Attachment. International Journal of Architecture and Urban Development, 3, no. 1, 5-12. http://ijaud.srbiau.ac.ir/pdf_581_a90b5ac919ddc57e6743d8ce 32d19741.html.

[13] Hay, R. 1998. Sense of place in developmental context. Journal of Environmental Psychology, 18, no. 1, 5-29.

[14] Heft, H. 2010. Affordances and the perception of landscape. Innovative Approaches to Researching Landscape and Health. Pp., 9-32. Oxon: Routledge.

[15] Heft, H., \& Chawla, L. 2006. 12 Children as agents in sustainable development: the ecology of competence. Children and their environments, 199-216.

[16] Jones, P., Meleis, A., \& Schumacher, K. 1999. Helping Elderly Persons in Transition: A Framework for Research and Practice, School of Nursing Departmental Papers, School of Nursing, University of Pennsylvania.

[17] Kasarda, J. D., \& Janowitz, M. 1974. Community Attachment in Mass Society. American Sociological Review, 39, no. 3, 328. Doi: $10.2307 / 2094293$.

[18] Kopec, D. 2018. Environmental Psychology for Design (3rd Ed.). New York, NY: Fairchild.

[19] Korpela, K. M. 1989. Place-identity as a product of environmental self-regulation. Journal of Environmental Psychology, 9, no. 3, 241-256.

[20] Korpela, K. M., Ylén, M., Tyrväinen, L., \& Silvennoinen, H. 2009. Stability of self- reported favorite places and place attachment over a 10-month period. Journal of Environmental Psychology, 29, 95-100. Doi: 10.1016/j.jenvp.2008.05.008.

[21] Lewicka, M. 2011. Place attachment: How far have we come in the last 40 years? Journal of Environmental Psychology, 31, no. $3,207-230$.

[22] Li, M. Y. 2012. Place attachment in university students: Social antecedents and academic motivations (Doctoral dissertation, University of Pittsburgh). Retrieved from http://d-scholarship.pitt.edu/6179/1/Manyu_MasterThesis_ET D_5th_revision.pdf.

[23] Lim, M., \& Barton, A. C. 2010. Exploring insideness in urban children's sense of place. Journal of Environmental Psychology, 30, no. 3, 328-337.

[24] Manzo, L. C., \& Devine-Wright, P. (Eds.) 2013. Place Attachment: Advances in Theory, Methods, and Applications. New York, NY: Routledge.

[25] Moore, L., \& Graefe, A. R. 1994. Attachments to recreation settings: The case of rail-trail users. Leisure Sciences, 16, 1731 .

[26] Morgan, P. 2010. Towards a developmental theory of place attachment. Journal of Environmental Psychology, 30, 11-22. Doi: 10.1016/j.jenvp.2009.07.001.

[27] Newman, O. 1996. Creating defensible space. U.S. Department of Housing and Urban Development. 
[28] Oishi, S., Kurtz, J. L., Miao, F. F., Park, J., \& Whitchurch, E. 2011. The role of familiarity in daily well-being: Developmental and cultural variation. Developmental Psychology, 47, no. 6, 1750-1756. Doi: 10.1037/a0025305.

[29] Proshansky, H. M., Fabian, A. K., \& Kaminoff, R. 1983. Place-identity: Physical world socialization of the self. Journal of environmental psychology, 3, no. 1, 57-83. Doi: $10.1016 / \mathrm{S} 0272-4944(83) 80021-8$.

[30] Relph, E. (1976). Place and Placelessness. London, UK: Pion.

[31] Sani, F. (2008). Schism in groups: A social psychological account. Social and Personality Psychology Compass, 2, no. 2, 718-732.

[32] Scannell, L., \& Gifford, R. 2017a. The experienced psychological benefits of place attachment. Journal of Environmental Psychology, 51, 256-269. Doi: 10.1016/j.jenp.2017.04.001.

[33] Scannell, L., \& Gifford, R. 2017b. Place attachment enhances psychological need satisfaction. Environment and Behavior, 49, no. 4, 359-389. Doi: 10.1177/0013916516637648.

[34] Stokols, D., \& Shumaker, S. A. 1981. People in places: a transactional view of settings. In J. Harvey (Ed.), Cognition, social behavior, and the environment (pp. 441-488). Hillsdale, NJ: Erlbaum.
[35] Strange, C. C., \& Banning, J. H. 2001. Educating by Design: Creating Campus Learning Environments That Work. San Francisco, CA: Jossey-Bass.

[36] Terrazas-Carrillo, E. C., Hong, J. Y., \& Pace, T. M. 2014. Adjusting to new places: International student adjustment and place attachment. Journal of College Student Development, 55, no. 7, 693-706. doi:10.1353/csd.2014.0070.

[37] Tuan, F. 1974. Topophilia: A Study of Environmental Perception, Attitudes, and Values. New York, NY: Columbia University Press.

[38] Twigger-Ross, C., Bonaiuto, M., \& Breakwell, G. 2003. Identity theories and environmental psychology. Psychological theories for environmental issues. Pp., 203-234.

[39] Vallerand, R. J., Pelletier, L. G., Blais, M. R., Briere, N. M., Senecal, C., \& Vallieres, F. 1992. The Academic Motivation Scale: A measure of intrinsic, extrinsic, and a motivation in education. Educational and Psychological Measurement, 52, no. 4, 1003-1017. Doi: 10.1177/0013164492052004025.

[40] Zajonc, R. B. 1968. Attitudinal effects of mere exposure. Journal of Personality and Social Psychology, 9, 2, Part, 2, 9-27. 